\title{
The Effect of PQ4R (Preview, Question, Read, Reflect, Recite, Review) Learning Method with Internet-Assisted on Learning Outcomes of Students SMA Labschool UNTAD Palu on Salt Hydrolysis
}

\author{
*Ersa William Lakukua, Mery Napitupulu \& Afadil \\ Pendidikan Kimia/FKIP - Universitas Tadulako, Palu - Indonesia 94119 \\ Received 12 December 2019, Revised 15 January 2019, Accepted 12 February 2020 \\ doi: 10.22487/j24775185.2020.v9.i1.pp27-33
}

\begin{abstract}
This study aimed to describe the effect of PQ4R learning methods with internet-assisted on students' learning outcomes of class XI SMA Labschool UNTAD Palu on salt hydrolysis material. The type of research was quasiexperimental with nonrandomized pretest-posttest control group design. This study was conducted with two groups, namely the XI IPA class 1 as the experimental group $(n=21)$ and the XI IPA class 3 as a control group $(n=23)$. The testing of the research data used a two-party t-test statistical analysis. The results of data analysis obtained that the average of an experimental class was 63.19 with a standard deviation of 7.37 and a control class was 57.22 with a standard deviation of 8.19. The results of testing the hypothesis with the two-party $t$-test statistics obtained $-t_{\text {table }}<t_{\text {count }}>+t_{\text {table }}\left(t_{\text {count }} 2.54\right.$ and $t_{\text {table }}$ 1.68) with a significance level $(\alpha)=0.05$ and degrees of freedom $(d k)=35$. Based on the results testing of the hypothesis, it can be concluded that $H_{0}$ was rejected and $H_{1}$ was accepted. This means that the PQ4R learning method with internet-assisted has a positive effect on the learning outcomes of students class XI SMA Labschool UNTAD Palu.
\end{abstract}

Keywords: PQ4R, internet, salt hydrolysis, learning outcomes

\section{Pendahuluan}

Pendidikan merupakan salah satu kebutuhan mendasar bagi setiap bangsa, karena melalui pendidikan warga negara akan siap dalam menghadapi setiap perubahan dan perkembangan zaman yang semakin pesat (Widiyanthi dkk., 2014). Pesatnya perkembangan ilmu pengetahuan dan teknologi, menuntut setiap manusia harus memiliki pengetahuan dan keterampilan yang baik dalam menghadapi perkembangan IPTEK diera globalisasi saat ini (Wijaya dkk., 2014).

Era globalisasi ditandai dengan adanya perubahan yang sangat cepat dalam dunia pendidikan. Perubahan tersebut dipacu oleh kemajuan Teknologi Informasi dan Komunikasi (TIK) termasuk di dalamnya pemanfaatan internet dalam membantu proses pembelajaran (Warsita, 2011).

Internet menjadi sarana yang memiliki peranan besar jika dimanfaatkan untuk kepentingan pembelajaran. Informasi dapat digali dengan mudah dan cepat, dengan dukungan lebih dari 30.000 konferensi elektronik on-line dapat menjadi modal dalam proses pembelajaran. Akses terhadap sumber pengetahuan yang dahulunya harus dengan buku cetakan, sekarang telah tergantikan dengan buku elektronik yang diakses melalui internet. Internet telah menjadi sumber belajar yang seolah tidak ada habisnya, tergantung dari penggunaan dan pemanfaatanya dalam suatu proses pembelajaran (Naim, 2017).

Pemanfaatam internet menjadi suatu hal yang perlu diperhatikan oleh pihak sekolah. Guru dituntut untuk dapat mengusai dan memiliki wawasan yang luas terhadap perkembangan ilmu pengetahuan dan teknologi informasi komunikasi terkini, sehinggapembelajaran yang efektif dan efisien dapat dihadirkan dengan mengoptimalkan internet yang ada di sekolah.

Sekolah Menengah Atas (SMA) di kota Palu yang secara konsisten ingin meningkatkan mutu dan kualitas pendidikan dengan memanfaatkan teknologi informasi dan komunikasi, salah satunya adalah SMA Labschool UNTAD Palu. Akreditasi A yang dimiliki sekolah sejak tahun 2016 serta ketersediaan jaringan internet yang memadai, mengindikasikan bahwa sekolah ini berupaya untuk terus menurus mengembangkan sistem pembelajarannya.

Internet sebagai salah satu teknologi yang dapat menjadi media sekaligus sebagai sumber belajar dalam mencari pengetahuan (Huzni, 2008). Namun, berkaitan dengan hal tersebut, jaringan internet yang tersedia ternyata belum secara optimal dimanfaatkan oleh siswa. Penyalahgunaan

${ }^{*}$ Correspondence:

Ersa William Lakukua

e-mail: ersalakukua@gmail.com

(c) 2020 the Author(s) retain the copyright of this article. This article is published under the terms of the Creative Commons Attribution License 4.0, which permits unrestricted non-commercial use, distribution, and reproduction in any medium, provided the original work is properly cited. 
pemanfaatan internet tersebut, berdampak pada hasil belajar siswa. Hasil belajar yang menurun tersebut tenyata ditemukan pada mata pelajaran kimia.

Berdasarkan wawancara yang dilakukan terhadap salah seorang guru kimia kelas XI IPA di sekolah tersebut, hasil belajar siswa pada mata pelajaran kimia materi hidrolisis garam berada pada tingkat keberhasilan yang rendah. Banyaknya siswa yang mendapat nilai rendah merupakan salah satu indikasi bahwa kebanyakan siswa belum memahami materi hidrolisis garam.

Hidrolisis garam tergolong salah satu materi yang sulit. Konsep dasar dari asam basa lemah, konsep titrasi dan larutan penyangga yang berkesinamungan, menuntut siwa untuk mampu memahami dan mengingat setiap materi yang telah diajarkan (Nurchayatun dkk., 2017). Pemahaman konsep-konsep tersebut pada siswa membutuhkan pemilihan metode pembelajaran yang sesuai. Kesesuaian antara karakteristik materi ajar dengan metode yang digunakan dalam pembelajaran akan berpengaruh terhadap hasil belajar siswa.Kesalahpahaman dapat disumbangkan oleh sifat abstrak dari konsep, yang diberikan oleh guru atau keyakinan yang terbentuk sebelumnya oleh siswa (Afadil \& Wahid, 2017).

Pembelajaran kooperatif memiliki kontribusi yang dapat mengembangankan keterampilan sosial siswa. Siswa dapatmengembangkan kemampuan empatik, kemampuan mencoba menemukan solusi masalah secara kelompok, dan juga mengembangkan keterampilan seperti kebutuhan untuk mengakomodasi pandangan orang lain (Kristiawan, 2014). Sejalan dengan hal tersebut, metode pembelajaran PQ4R menjadi pilihan yang tepat untuk mendukung terciptanya pengembangan pembelajaran.

Metode PQ4R digunakan untuk membantu siswa memahami apa yang mereka baca dan pelajari serta membantu guru melaksanakan proses belajar mengajar di kelas dengan kegiatan membaca buku. PQ4R merupakan sebuah singkatan dari preview (membaca selintas dengan cepat), question (bertanya), read (membaca), reflect (refleksi), recite

Tabel 1. Desain penelitian non randomized pretest-posttest control group design

\begin{tabular}{cccc}
\hline Kelompok & Pretest & Perlakuan & Postest \\
\hline Kelas eksperimen & $\mathrm{Y}_{1}$ & $\mathrm{X}_{1}$ & $\mathrm{Y}_{2}$ \\
Kelas Kontrol & $\mathrm{Y}_{1}$ & $\mathrm{X}_{2}$ & $\mathrm{Y}_{2}$ \\
\hline
\end{tabular}

Dimana $Y_{1}$ adalah Pretest materi Hidrolisis Garam; $\mathrm{Y}_{2}$ adalah Posttest materi Hidrolisis Garam; $\mathrm{X}_{1}$ adalah Metode pembelajaran $P Q 4 R$ berbantuan internet; dan $X_{2}$ adalah Metode pembelajaran $P Q 4 R$, tetapi tanpa berbantuan internet

Populasi pada penelitian ini adalah seluruh siswa kelas XI IPA SMA Labschool UNTAD Palu yang terdaftar pada tahun ajaran 2017/2018 yang terdiri dari 3 kelas yaitu XI IPA 1 berjumlah 21 orang, XI IPA 2 berjumlah 21 orang dan XI IPA 3 berjumlah 23 orang. Sampel penelitian diambil dari populasi dengan menggunakan teknik purposive (tanya-jawab sendiri), review (mengulang secara menyeluruh) (Trianto, 2007). Dengan menggunakan metode PQ4R siswa dapat menemukan sendiri informasi melalui membaca, memaknai bahan bacaan, serta mengingat apa yang mereka baca melalui langkah-langkah pembelajaran PQ4R sehingga informasi tersebut dapat menjadi lebih bermakna (Sudiarti dkk., 2015).

Penerapan metode pembelajaran ini merupakan terobosan yang dapat digunakan sebagai alternatif untuk membantu siswa mengasah kemampuan dan potensi diri. Peran guru berubah menjadi peran sebagai fasilitator, artinya guru lebih banyak sebagai orang yang membantu siswa untuk belajar, sehingga pembelajaranlebih berpusat pada siswa (student centered) (Ramdiah, 2013).

Metode pembelajaran PQ4R akan lebih efektif dan menarik bila didukung denganmedia pembelajaranyang dapat menghidupkan susana kelas, karena metode ini lebih menekankan siswa membaca suatu bacaan. Sehingga dengan pemanfaatan internet yang baik dalam suatu pembelajaran akan dilakukan secara teratur melalui langkah-langkah pembelajaran PQ4R. Terciptanya kondisi pembelajaran yang efektif dan efisien melalui metode PQ4R berbantuan internet, diharapkan dapat meningkatkan hasil belajar siswa.

Tulisan ini dimaksudkan untuk mendeskripsikan apakah PQ4R dengan pendekatan internet mempengaruhi suatu hasil belajar siswa.

\section{Metode}

Jenis penelitian ini adalah quasi eksperiment atau eksperimen semu. Jenis penelitian ini berusaha menentukan apakah suatu treatment mempengaruhi hasil sebuah penelitian. Pengaruh ini dinilai dengan cara menerapkan treatment tertentu pada satu kelompok (kelompok eksperimen) dan tidak menerapkannya pada kelompok lain (kelompok kontrol) (Creswell, 2009), dengan desain penelitian ini nonrandomized pretest-posttest control group designatau pretes-postes group kontrol tidak secara random (Sukardi, 2008), yang dapat dilihat pada Tabel 1 .

sampling, yaitu teknik pengambilan sampel berdasarkan pertimbangan tertentu(Sugiyono, 2012). Teknik pengambilan sampel berdasarkan nilai rata-rata hasil belajar siswa di semester sebelumnya dan hasil wawancara dengan guru yang mengajar. Pertimbangan lainnya juga didasarkan pada jumlah siswa yang memiliki handpone dan laptop yang nantinya akan mendukung proses pembelajaran berbantuan internet. Kelas XI IPA IPA 3 ditetapkan sebagai kelas kontrol dan kelas XI IPA 1 sebagai kelas eksperimen. 
Instrumen yang dalam penelitian ini adalahlembar observasi aktivitas guru dan siswa selama proses pembelajaran, Rencana Pelaksanaan Pembelajaran (RPP) dan tes hasil belajar. Lembar observasi aktivitas guru dan siswa digunakan untuk mengumpulkan data aktivitas siswa dan kinerja guru selama proses pembelajaran. Lembar observasi diisi oleh observer sesuai dengan obyek yang diamati, baik guru maupun siswa. Lembar observasi yang digunakan berupa daftar cocok (chek list) yang berisi deretan pertanyaan, dimana responden yang dievaluasi membubuhkan tanda centang $(\sqrt{ })$ di tempat yang sudah disediakan (Arikunto, 2007), RPP digunakan sebagai panduan bagi guru dalam melaksanakan kegiatan pembelajaran di kelas agar tujuan pembelajaran dapat tercapai dengan baik daninstrument tes berupa soal pilihan ganda sebanyak 40 butir soal yang terlebih dahulu divalidasi. Validasi dilakukan dengan dua acara, yaitu validasi teori oleh ahli dan validasi empirik oleh siswa yang telah mendapatkan materi hidrolisis garam yaitu siswa kelas XII IPA SMA Labschool UNTAD Palu. Tes hasil belajar dimaksudkan untukmemperoleh gambaran mengenai pengaruhmetode pembelajaran yangtelah diterapkan.

Teknik analisis data yang digunakan yaitu teknik analisis statistik deskriptif dan statistik inferensial. Hasil perhitungan statistik inferensial adalah dengan menentukan hubungan nilai pretest dan posttest pada kelas eksperimen maupun kelas kontrol dengan menggunakan uji $N$-gain (Hake, 2002). Selanjutnya, untuk analisis statistik inferensial, terlebih dahulu dilakukan uji prasyarat berupa uji normalitas dan uji homogenitas. Analisis statistik inferensial dilakukan setelah data yang yang diperoleh berdistribusi normal dan bersifat homogen. Pada analisis statistik inferensial, metode analisis data yang digunakan untuk menguji hipotesis dalam penelitian ini berupauji-t dua pihak (Herdianto dkk., 2014).

\section{Hasil dan Pembahasan}

Hasil analisis data yang diperoleh selama kegiatan pembelajaran berupa lembar observasi aktivitas guru dan siswadisajikan pada Tabel 2 dan 3.

Tabel 2. Hasil penilaian aktivitas guru dan siswa pada kelas eksperimen

\begin{tabular}{cccccc}
\hline \multirow{2}{*}{ Uraian } & \multicolumn{4}{c}{ Kelas Eksperimen } \\
\cline { 2 - 6 } & \multicolumn{2}{c}{ Aktivitas } & \multicolumn{2}{c}{ Aktivitas } \\
& \multicolumn{2}{c}{ Guru } & \multicolumn{2}{c}{ Siswa } \\
\hline Pertemuan & 1 & 2 & 1 & 2 \\
Persentase (\%) & 83.33 & 85.16 & 80 & 84 \\
Rata-rata (\%) & \multicolumn{2}{c}{84.24} & \multicolumn{2}{c}{82} \\
\hline
\end{tabular}

Berdasarkan data pada Tabel 2 dapat dilihat bahwa aktivitas guru dan siswa dalam pembelajaran dengan menggunakan metode PQ4R berbantuan internet atau kelas eksperimen termasuk pada kategori baik.

Tabel 3. Hasil penilaian aktivitas siswa dan guru pada kelas control

\begin{tabular}{cccccc}
\hline \multirow{2}{*}{ Uraian } & \multicolumn{4}{c}{ Kelas Kontrol } \\
\cline { 2 - 6 } & \multicolumn{2}{c}{ Aktivitas } & \multicolumn{2}{c}{ Aktivitas } \\
& \multicolumn{2}{c}{ Guru } & \multicolumn{3}{c}{ Siswa } \\
\hline Pertemuan & 1 & 2 & 1 & 2 \\
Persentase (\%) & 80.39 & 81.48 & 80 & 82 \\
Rata-rata (\%) & \multicolumn{2}{c}{80.93} & \multicolumn{2}{c}{81} \\
\hline
\end{tabular}

Berdasarkan data pada Tabel 3 dapat dilihat bahwa aktivitas guru dan siswa dalam pembelajaran dengan menggunakan metode PQ4R tanpa berbantuan internet atau kelas kontrol juga termasuk dalam kategori baik. Hal tersebut didukung oleh Sudjana, (2012) kemampuan yang dituntut dalam pelaksanaan proses belajar mengajar adalah keaktifan guru dalam menciptakan dan menumbuhkan kegiatan belajar sesuai dengan rencana yang telah disusun dan persentase ketercapaian sebesar $80 \%$ atau berkategori baik dan sangat baik.

Penilaian aktivitas guru selama proses pembelajaran menjadi salah satu pendukung keunggulan metode PQ4R berbantuan internet. Kekurangan-kekurangan pada peretemuan pertama dalam menerapkan metode pembelajaran PQ4R dengan bantuan internet diperbaiki pada pertemuan selanjutnya. Masalah tersebut diatasi dengan cara memberikan arahan kepada siswa untuk mempersiapkan diri sebelum pembelajaran dimulai dan memberikan kesempatan bertanya kepada siswa dengan intensitas yang lebih banyak dari pertemuan sebelumnya pada saat proses pembelajaran. Guru juga memotivasi siswa untuk berani mengajukan pertanyaan dengan cara memberi penghargaan kepada siswa yang berani bertanya atau mengajukan pendapat dengan memberi tepuk tangan atau 
respon positif berupa pujian. Membimbing siswa bekerjasama dan saling tukar pendapat dengan kelompoknya dapat menuntut siswa untuk saling menghargai pendapat dan menyelesaiakan soal-soal yang diberikan oleh guru. $\mathrm{Hal}$ tersebut mempermudah siswa menyelesaiakan pemecahan masalah dan tugas yang diberikan oleh guru.

Persentase nilai rata-rata akitivitas siswa setiap pertemuan menunjukan kenaikan yang cukup signifikan. Kenaikan aktifitas siswa setiap pertemuan disebabkan karena guru terus berusaha untuk meningkatkan pemahaman dan aktifitas kepada siswa dengan berbagai perlakuan agar siswa lebih aktif dalam pembelajaran. Faktor-faktor yang mempengaruhi aktivitas siswa selama proses pembelajaran salah satunya seperti siswa yang cenderung diam (tidak bertanya) pada saat kegiatan belajar mengajar berlangsung, sehingga kesulitan dalam menyelesaikan soal.

Keterlaksanaan RPP yang diterapkan pada kelas eksperimen dan kelas kontrol di SMA Labschool UNTAD Palu disajikan pada Tabel 4.

Tabel 4. Data keterlaksanaan RPP

\begin{tabular}{ccccc}
\hline Uraian & \multicolumn{2}{c}{ Kelas Eksperimen } & \multicolumn{2}{c}{ Kelas Kontrol } \\
\hline Pertemuan & 1 & 2 & 1 & 2 \\
Alokasi Waktu (Menit) & 90 & 90 & 90 & 90 \\
Persentase Keterlaksanaan (\%) & 87.5 & 89.28 & 85.7 & 87.50 \\
Rata-rata Persentase Keterlaksanaan (\%) & \multicolumn{2}{c}{88.39} & & 86.6
\end{tabular}

Rata-rata penilaian keterlaksanaan RPP kelas eksperimen menunjukan kategori baik dengan perolehan penilaian sebesar 88,39, lebih tinggi dibandingkan kelas kontrol mencapai dengan nilai rata-rata $86,6 \%$ dengan kategori baik. Hasil demikian menunjukkan bahwa pembelajaran telah berlangsung sesuai rencana yang tertuang pada RPP. Menurut Sudjana, (2012), kemampuan yang dituntut dalam pelaksanaan proses belajar mengajar adalah keaktifan guru dalam menciptakan dan menumbuhkan kegiatan belajar sesuai dengan rencana yang telah disusun dan persentase ketercapaian sebesar $80 \%$ atau berkategori baik dan sangat baik.

Hasil belajar siswa diperoleh dari tes pilihan ganda yang diberikan setelah pembelajaran secara keseluruhan untuk materi hidrolisis garam berakhir (Posttesti). Posttes yang dilakukan bertujuan untuk mengetahui sejauh mana pengaruh metode PQ4R berbantuan internet terhadap hasil belajar siswa kelas XI IPA pada materi hidrolisis garam. Diperoleh data dari kelas eksperimen dan kelas kontrol seperti pada Tabel 5.

Tabel 5. Perbandingan hasil belajar siswa kelas eksperimen dan kelas kontrol

\begin{tabular}{ccccc}
\hline \multirow{2}{*}{ Uraian } & \multicolumn{2}{c}{ Tes Awal } & \multicolumn{2}{c}{ Tes Akhir } \\
\cline { 2 - 5 } & Kelas Eksperimen & Kelas Kontrol & Kelas eksperimen & Kelas kontrol \\
\hline Sampel & 21 & 23 & 21 & 23 \\
Nilai terendah & 15 & 15 & 50 & 40 \\
Nilai tertinggi & 60 & 60 & 75 & 70 \\
Skor rata-rata & 35,95 & 30,21 & 63,19 & 57,22 \\
Standar deviasi & 11,25 & 12,83 & 7,37 & 8,19 \\
\hline
\end{tabular}

Berdasarkan hasil yang diperoleh setelah melakukan tes awal dan tes akhir, diperoleh data deskriptif untuk pengujian N-Gain. Pengujian $<\mathrm{g}>$ dilakukan untuk menganalisis data dengan cara mendeskripsikan atau menggambarkan data yang telah terkumpul berdasarkan pencapaian masingmasing variabel dalam hubungan nilai pretest dan posttest siswa pada kelas eksperimen dan kelas kontrol. Hasil pengujian N-Gain disajikan pada Tabel 6 .

Tabel 6. Hasil Pengujian N-Gain

\begin{tabular}{lllll}
\hline Kelas & Pretest & Posttest & $\langle g\rangle$ & Kategori \\
\hline Eksperimen & 35.95 & 63.19 & 0.45 & Sedang \\
Kontrol & 30.21 & 57.22 & 0.40 & Sedang \\
\hline
\end{tabular}

Hasil belajar siswa menunjukan peningkatan setelah pembelajaran dilakukan guru pada kelas eksperimen memiliki rata-rata 0.45 dan pada kelas kontrol memiliki rata-rata 0.40 . Artinya, peningkatan hasil belajar siswa sebelum dan sesudah pembelajaran berada pada kategori sedang (Hake, 2010). Hal ini dipengaruhi oleh beberapa faktor pada saat menerapkan pembelajaran metode PQ4R yaitu pada pertemuan pertemuan pertama sebagian siswa terlihat malas untuk terlibat dalam kegiatan eksperimen meskipun sebagian siswa lain mengaku senang dengan kegiatan eksperimen ini. Pada saat diskusi banyak siswa yang terlihat malu untuk terlibat menyampaikan pendapatnya dalam diskusi, sebagian siswa lebih senang dengan gaya belajar guru yang menerangkan materi pembelajaran. 
Hasil perhitungan uji normalitas kelas eksperimen diperoleh data $x^{2}$ bitung $=6.71 \mathrm{dan} x_{\text {tabel }}^{2}=$ 7.81. Sehingga dapat disimpulkan bahwa data tersebut terdistribusi normal karena memenuhi kriteria data terdistribusi normal yaitu $x^{2}{ }_{\text {hitung }} \leq x_{\text {tabel }}^{2}$ yaitu $6.71 \leq 7.81$. Sedangkan hasil kelas kontrol diperoleh data $x^{2}$ hitung $=2.92$ dan $x_{\text {tabel }}^{2}=7.81$. Sehingga dapat disimpulkan bahwa data tersebut terdistribusi normal karena memenuhi kriteria data terdistribusi normal yaitu $x_{\text {hitung }}^{2} \leq x_{\text {tabel }}^{2}$ yaitu $2.92 \leq$ 7.81 .

Hasil nilai pengujian homogentas suatu data menggunakan uji $\mathrm{F}$ (kesamaan dua varians) dan diperoleh varians terbesar $=8,19$ dan varians terkecil $=7,73$. Diperoleh nilai Fhitung $=1,05$ dan Ftabel $=$ 2,07 sehingga disimpulkan bahwa data tersebut memenuhi kriteria data homogen yaitu Fhitung < Ftabel yaitu $1,05<2,07$.

Sebelum melaukan analisis inferensial dengan menggunakan uji-t dua pihak, terlebih dahulu digunakan uji prasyarat yaitu uji normalitas dan uji homogenitas. (Herdianto dkk., 2014) menyatakan, uji normalitas bertujuan untuk menentukan apakah data yang telah diperoleh terdistribusi normal atau tidak. Sedangkan uji homogenitas digunakan untuk mengetahui apakah data kedua varian kelas adalah homogen atau tidak.

Hasil analisis data inferensial yang menggunakan uji-t dua pihak pada kedua kelas yaitu kelas eksperimen dan kelas kontrol menunjukkan bahwa data berdistribusi normal dan variansnya homogen, serta analisis uji t-dua pihak diperoleh $-\mathrm{t}_{\text {tabel }} \leq \mathrm{t}_{\text {hitung }} \geq+\mathrm{t}_{\text {tabel }}\left(\mathrm{t}_{\text {hitung }}=2.54\right.$ dan $\mathrm{t}_{\text {tabel }}$ = 1.68) yang memperlihatkan bahwa jelas berada pada daerah penolakan $\mathrm{H}_{0}$ sehingga $\mathrm{H}_{0}$ ditolak dan $\mathrm{H}_{\mathrm{a}}$ diterima, maka dapat dikatakan bahwa metode pembelajaran PQ4R berbantuan internet berpengaruh positif terhadap hasil belajar siswa.

Beberapa alasan yang dapat dijadikan dasar penentuan bahwa metode PQ4R berbantuan internet relatif lebih baik dalam penyediaan peluang pencapain hasil belajar yang maksimal dibandingkan metode PQ4R tanpa internet adalah sebagai berikut.

Pertama, dilihat dari segi landasan teoritis, metode PQ4R merupakan salah satu bagian dari strategi elaborasi (Wijaya dkk., 2014). Menurut Heriyati (2017) elaboration merupakan pengembangan materi pembelajaran dan menjadikan pembelajaran itu lebih bermakna bagi siswa.

Strategi elaborasi membantu pemindahan informasi baru dari memori jangka pendek ke memori jangka panjang dengan menciptakan gabungan dan hubungan antara informasi baru dengan apa yang telah diketahui. Tiga metode dalam strategi elaborasi yaitu pembuatan catatan, analogi dan PQ4R (Linayaningsih, 2011).

Menurut Wahono (2014), aktivitas PQ4R dirancang untuk meningkatkan kedalaman memproses informasi bacaan. Metode PQ4R adalah suatu metode membaca yang digunakan untuk membantu siswa berpikir kritis dan memanfaatkan daya ingat siswa yang dapat membantu siswa memahami suatu bacaan didasari oleh teori belajar penemuan yang menyarankan agar siswa hendaknya belajar melalui berpartisipasi aktif dengan konsepkonsep dan prinsip-prinsip agar mereka memperoleh pengalaman dan melakukan eksperimen-eksperimen yang mengizinkan mereka untuk menemukan konsep dan prinsip itu sendiri. Pengetahuan yang diperoleh dengan menemukan sendiri akan berdampak baik pada diri siswa diantaranya pengetahuan itu bertahan lama atau lama diingat, dengan menemukan sendiri akan berdampak pada hasil belajar yang lebih baik.

Kedua, dilihat dari sudut pandang operasional empiris dalam penyajian pembelajaran, kelompok siswa yang belajar menggunakan metode PQ4R difasilitasi dengan bantuan internet menjadi pendukung pelaksanaan pembelajaran PQ4R. Internet difungsikan sebagai salah satu sumber informasi yang mendukung pelaksanaan metode pembelajaran $\mathrm{PQ} 4 \mathrm{R}$ yang diharapkan dapat memperkaya literatur siswa. Informasi yang diperoleh peneliti setelah melakukan searching di internet melalui www.google.comdiperoleh bahwa materi Hidrolisis Garam tersedia di 232.000 situs. Sumber informasi yang sebanyak itu tentunya sangat berguna jika dimanfaatkan oleh siswa sebagai bahan tambahan dalam memperoleh informasi selain dari buku paket yang digunakan di sekolah sehingga pengetahuan siswa akan lebih kaya dan akhirnya akan berdampak pada hasil belajar siswa yang memuaskan tanpa harus mengeluarkan biaya dan waktu yang lebih, apalagi dari pihak SMA Labschool UNTAD Palu telah menyediakan fasilitas jaringan internet secara gratis untuk siswanya. Hal tersebut sejalan dengan Ifeoma dkk., (2016) menyatakan, fasilitas internet yang ada di sekolah akan mempermudahkan siswa untuk mencari informasi dalam proses pembelajaran

Penilaian aktivitas guru selama proses pembelajaran menjadi pendukung keunggulan metode PQ4R berbantuan internet. Hasil observasi menunjukan rata-rata aktivitas guru dengan metode PQ4R berbantuan internet adalah $84.24 \%$ dengan kategori baik, sedangkan aktivitas guru dengan metode PQ4R tanpa bantuan internet adalah 80.93\% dengan katergori baik. Metode PQ4R dengan bantuan internet, akan menjadi penolong terciptanya suatu pembelajaran yang menarik dan meningkatnya hasil belajar.

Selanjutnya, rata-rata penilaian keterlaksanaan RPP kelas eksperimen menunjukan kategori baik dengan perolehan penilaian sebesar 88.39, lebih tinggi dibandingkan kelas kontrol mencapai dengan nilai rata-rata $86.6 \%$ dengan kategori baik. Hasil demikian menunjukkan bahwa pembelajaran telah berlangsungsesuai rencana yang tertuang pada RPP. Menurut Sudjana, (2012), kemampuan yang dituntut dalam pelaksanaan proses belajar mengajar adalah keaktifan guru dalam 
menciptakan danmenumbuhkan kegiatan belajar sesuai dengan rencana yang telah disusun dan persentase ketercapaian sebesar $80 \%$ atau berkategori baik dan sangat baik.

Berdasarkan pemaparan tersebut, secara teoritis, empiris dan dukungan lembar observasi aktivitas guru dan siswa serta keterlaksanaan RPP, metode pembeajaran PQ4R berbantuan internet lebih berpengaruh dibandingkan dengan metode pembelajaran PQ4R tanpa bantuan internet dalam pencapaian hasil belajar. Hal tersebut didukung Oleh Indrawati \& Riyadi (2011) dalam penelitian tentang pengaruh metode pembelajaran preview, question, read, reflect, recite, and review (PQ4R) terhadap kemampuan membaca pemahaman siswa. Hasil yang diperoleh menyatakan bahwa metode pembelajaran PQ4R menghasilkan kemampuan membaca pemahaman yang lebih baik dibandingkan dengan metode pembelajaran pemberian tugas. Dengan demikian metode pembelajaran PQ4R berbantuan internet dapat menjadi salah satu pilihan yang tepat digunakan dalam proses pembelajaran materi Hidrolisis Garam pada siswa kelas XI IPA SMA.

\section{Kesimpulan}

Metode pembelajaran PQ4R berbantuan internet berpengaruh positif terhadap hasil belajar siswa kelas XI IPA SMA Labschool UNTAD Palu pada materi hidrolisis garam. Hal tersebut dilihat dari skor rata-rata postest masing-masing kelas, yaitu kelas eksperimen yaitu 63.19 dan kelas kontrol 57.22.

\section{Ucapan Terima kasih}

Penulis mengucapkan terima kasih kepada kepala SMA Labschool UNTAD Palu dan guru mata pelajaran kimia SMA Labschool UNTAD Palu serta semua pihak yang banyak membantu penulis dalam menyelesaikan penelitian ini.

\section{Referensi}

Afadil, \& Diah, A. W. M. (2017). Effectiveness of learning materials with science-philosophy oriented to reduce misconception of students on chemistry. Proceedings First Indonesian Communication Forum of Teacher Training and Education Faculty Leaders International Conference on Education 2017. Amsterdam: Atlantis Press.

Arikunto, S. (2007). Manajemen penelitian. Jakarta: Rineka cipta.

Creswell, J. W. (2009). Research design pendekatan kualitatif, kuantitatif, dan mixed. Jakarta: Pustaka Pelajar.

Hake, R. (2002). Relationship of individual student normalized learning gains in mechanics with gender, high-school physics, and pretest scores on mathematics and spatial visualization. Indiana University.

Herdianto, K., Sudhita, I. W. R., \& Sedanayasa, G.
(2014). Pengaruh model pembelajaran murder terhadap pemahaman konsep IPA siswa kelas V SD di gugus I kecamatan Buleleng. Jurnal Mimbar PGSD Universitas Pendidikan Ganesha, 2(1), 1-10.

Heriyati. (2017). Pengaruh model pembelajaran elaborasi terhadap hasil belajar matematika. Susunan Artikel Pendidikan (SAP), 2(1), 7583.

Huzni, I. S. (2008). Pemanfaatan media internet sebagai sumber belajar. Jurnal Iqra, 2(2), 72 83.

Ifeoma, N. A., U., Onwudinjo. O. T., Obioma, O. L., \& Njideka, A. A. (2016). The need for integrating internet facility in the tertiary institutions' curriculum in Nigeria. International Journal of Innovative Research and Development, 5(9), 267-269.

Indrawati, T., Riyadi, \& Matsuri. (2014). Pengaruh metode pembelajaran preview, question, read, reflect, recite, and review (PQ4R) terhadap kemampuan membaca pemahaman. Jurnal Didaktika Dwija Indra, 2(9), 1-6.

Kristiawan, M. (2014). The implementation of cooperative learning in english class of favorite school of secondary high school 5 Batusangkar, West Sumatera. International Journal of Educational Administration and Policy Studies, 6(2), 23-31.

Linayaningsih, F. (2011). Metode PQ4R (preview, question, read, reflect, recite, review) untuk meningkatkan prestasi belajar pendidikan kewarganegaraan. Majalah Ilmiah Informatika, 2(2), 75-86.

Naim, N. (2017). Dasar-dasar komunikasi pendidikan. Jogjakarta: AR-RUZZ MEDIA.

Nurchayatun, D., Nuroho, A., Saputro, C., \& Yamtinah, S. (2017). Penerapan model pembelajaran student team achievement division (STAD) dilengkapi media word square untuk meningkatkan minat dan prestasi belajar pada materi tata nama senyawa kimia siswa kelas X IPS 2 SMA N 2 Sukoharjo tahun pelajaran 2015/2016. Jurnal Pendidikan Kimia, 6(1), 16-23.

Ramdiah, S. (2013). Pengaruh strategi pembelajaran PQ4R terhadap keterampilan metakognitif dan hasil belajar biologi siswa putra dan putri kelas XI SMA di kota Banjarmasin. Seminar Nasional X Pendidikan Biologi FKIP UNS, 10(2), 1-7.

Sudiarti, N. K., Suwarta, I. W., \& Kusmariyanti, N. N. (2015). Pengaruh strategi pembelajaran PQ4R berbantuan internet terhadap hasil belajar IPA siswa kelas IV SD. E-Journal PGSD Universitas Pendidikan Ganesha, 3(1), $1-10$.

Sudjana, N. (2012). Penilaian hasil proses belajar 
mengajar. Bandung: PT. Remaja Rosdakarya Offset.

Sugiyono. (2012). Metode penelitian pendidikan (pendekatan kuantitatif, kualitatif, dan R\&D). Bandung: Alfabeta.

Sukardi. (2008). Metodologi penelitian pendidikan. Jakarta: PT Bumi Aksara.

Trianto. (2007). Model-model pembelajaran inovatif berorientasi konstruktivistik. Jakarta: Prestasi Pustaka.

Wahono, S. S. (2014). Using PQ4R to increase the students' reading comprehension at albidayah islamic boarding school Jember. Fenomena, 13(2), 121-132.
Warsita, B. (2011). Pendidikan jarak jauh perancangan, pengembangan, implementasi dan evaluasi diklat. Bandung: PT Remaja Rosdakarya.

Widiyanthi, I, A., Sugihartini, N., Seri, W. D., \& Antara, K. M. W. (2014). Pengaruh metode pembelajaran PQ4R (preview, question, read, reflect, recite, review) terhadap hasil belajar TIK siswa kelas VIII (studi kasus: SMP Negri 1 Sukasada tahun pelajaran 2013/2014. Karmapati, 3, 34-38.

Wijaya, I. M. A. P., Wirya, N., \& Suwarta, I. G. I. W. (2014). Pengaruh metode pembelajaran PQ4R terhadap hasil belajar IPA siswa Kelas VIII di SMP negeri 1 Sawan. Jurnal Teknologi Pendidikan, 2(1), 1-10. 